\title{
Involvement of Menaquinone in the Active Accumulation of Aminoglycosides by Bacillus subtilis
}

\author{
By HARRY W. TABER, ${ }^{*}+$ BARRY J. SUGARMAN \\ GERALD M. HALFENGER § \\ Department of Microbiology, University of Rochester School of Medicine and Dentistry, \\ Rochester, New York 14642, U.S.A. and Department of Microbiology and Immunology, Neil \\ Hellman Medical Research Building, Albany Medical College of Union University, Albany, \\ New York 12208, U.S.A.
}

(Received 5 August 1980; revised 29 September 1980)

\begin{abstract}
Accumulation of aminoglycoside antibiotics by bacteria requires energy, and it appears that this must be derived from electron transport occurring within the cytoplasmic membrane. Dependence of aminoglycoside accumulation on cellular menaquinone content was examined using a menaquinone auxotroph of Bacillus subtilis. This dependence manifested itself only when the menaquinone concentration was decreased to less than $10 \%$ of normal. The restricted aminoglycoside accumulation observed under these conditions was closely correlated with susceptibility to growth inhibition by the antibiotics. Evidence of saturation of the accumulation system was observed at low menaquinone concentrations, an effect not seen when menaquinone deficiency was relieved by supplying adequate shikimic acid (a menaquinone precursor) to the auxotroph. Lipophilic quinones may play two roles in aminoglycoside accumulation by bacteria: (i) as a binding site or part of a carrier complex; and (ii) as a crucial component of the electron transport system in maintaining the proton electrochemical gradient.
\end{abstract}

\section{INTRODUCTION}

The active accumulation of aminoglycoside antibiotics by bacteria is an energy-dependent process (Bryan \& Van den Elzen, 1977), inducible by aminoglycosides, and related to polycation accumulation (Höltje, 1978, 1979a, b; Bryan et al., 1980). Bryan and his co-workers (Bryan \& Van den Elzen, 1976, 1977; Bryan et al., 1976, 1980) have examined the uptake of streptomycin and of gentamicin by mutants of Escherichia coli and of Pseudomonas aeruginosa defective in the formation of electron transport components, in membrane energization, or in oxidative phosphorylation (unc mutants). All of these mutants exhibited decreased accumulation of aminoglycosides, with the exception of certain $u n c^{-}$and bacteriocin-insensitive strains that had enhanced uptake and were hypersensitive to aminoglycosides. Muir \& Wallace (1979) have used the latter property to isolate new uncA and $u n c B$ mutants of $E$. coli and have found these hypersensitive strains to accumulate aminoglycosides more rapidly than $u n c^{+}$revertants derived from them. Thorbjarnardottir et al. (1978) have isolated chromosomal mutants of $E$. coli that are resistant to low concentrations of several different aminoglycosides. The single mutations causing these multiple resistance phenotypes were mapped into the ribosomal protein loci, the unc locus and

\footnotetext{
† Present address: Department of Microbiology and Immunology, Neil Hellman Medical Research Building. Albany Medical College of Union University, Albany, New York 12208, U.S.A.

$\ddagger$ Present address: Department of Biochemistry and Molecular Biology, Northwestern University, Evanston. Illinois 60201 , U.S.A.

$\S$ Present address: Fisher Scientific Co., 15 Jet View Drive, Rochester, New York 14624, U.S.A.
} 
the ecfB locus (Plate, 1976). Multiple aminoglycoside resistance (mar) mutants of Bacillus subtilis that are defective in the membrane-bound electron transport system show lowered aminoglycoside uptake rates (Taber \& Halfenger, 1976; Taber et al., 1972). One of these mutants, strain RB163(men), has a conditionally decreased cellular content of menaquinone, dependent on the concentration of shikimic acid in the growth medium. This strain carries the aroD163(men) mutation (Farrand \& Taber, $1973 \mathrm{a}$, b; Taber et al., 1972), and is deficient in amino acid transport (Bisschop et al., 1975) and kanamycin accumulation (Taber \& Halfenger, 1976) when made phenotypically $\mathrm{Men}^{-}$by omission of shikimic acid. There are two distinct $\mathrm{Men}^{-}$phenotypes (Farrand \& Taber, $1973 \mathrm{a}$, b; Taber et al., 1972): (i) at cellular menaquinone concentrations of about $8 \%$ or greater of the normally regulated concentration, there are normal concentrations of cytochromes $a, b$ and $c$, and oxygen consumption is not diminished; (ii) if menaquinone deficiency is more severe, then respiration and normal regulation of cytochrome synthesis are compromised. The present study explores the consequences of these partial and severe menaquinone deficiencies on aminoglycoside accumulation by Bacillus subtilis, and the accompanying changes in susceptibility to growth inhibition by these antibiotics.

\section{METHODS}

Bacterial strain. Bacillus subtilis strain RB163(men) is a derivative of strain 168 and has the genotype trpC2 aroD163. Its properties have been described in detail (Farrand \& Taber, $1973 \mathrm{a} . \mathrm{b}$ ). The menaquinone content of this strain is reproducibly dependent on the shikimic acid concentration in the growth medium.

Media. Tryptose blood agar base (TBAB; Difco) was used for routine culturing on solid media. TG medium (tryptose-beef extract medium $+0.2 \%$ glucose) has been described previously (Farrand \& Taber, 1973 b; Taber \& Halfenger, 1976). SMG (Supplemented minimal medium plus glucose) was Spizizen's minimal salts (M) medium (Anagnostopoulos \& Spizizen, 1961) containing $0.4 \%(\mathrm{w} / \mathrm{v})$ glucose, $0.1 \%(\mathrm{w} / \mathrm{v})$ Casamino acids and $50 \mu \mathrm{g}$ tryptophan $\mathrm{ml}^{-1}$.

Growth. To estimate growth rates, the turbidity of liquid shake cultures was measured at $540 \mathrm{~nm}$ as described previously (Farrand \& Taber, 1973 a). Cells were always grown at $37^{\circ} \mathrm{C}$.

Antibiotic accumulation. Strain RB163(men) was grown overnight in SMG medium containing shikimic acid $\left(0.01\right.$ to $5.0 \mu \mathrm{g} \mathrm{ml}^{-1}$, depending upon the experiment). After inoculation into SMG medium with shikimic acid at the same concentration, cultures were shaken until the $A_{540}$ reached approximately $0 \cdot 3$. After rapid filtration of the culture through $0.45 \mu \mathrm{m}$ Millipore filters, the collected cells were resuspended in Spizizen's medium containing 50 $\mu \mathrm{g}$ tryptophan $\mathrm{ml}^{-1}(\mathrm{M}+\operatorname{trp})$, refiltered, and resuspended in $\mathrm{M}+\operatorname{trp}$ to an $A_{540}$ of about $0 \cdot 3$. This cell suspension was shaken at $37^{\circ} \mathrm{C}$ for $3 \mathrm{~min}$, after which glucose and Casamino acids were added to final concentrations characteristic of SMG. Sufficient shikimic acid was added to give a final concentration equal to that in which the culture had been grown. Unlabelled gentamicin sulphate $\left(19.4 \mu \mathrm{g} \mathrm{m}{ }^{-1}\right.$ final concentration) was added, and the cells were shaken for $4 \mathrm{~min} .{ }^{3} \mathrm{H} \mid \mathrm{Gentamicin}$ sulphate $\left(0.67 \mu \mathrm{Ci} \mathrm{m}^{-1}\right.$ final specific activity) was then added, to give a final gentamicin concentration of $23 \mu \mathrm{g} \mathrm{ml} l^{-1}$. Samples $(1.0 \mathrm{ml})$ were taken at $1.5 \mathrm{~min}$ intervals and filtered rapidly on to polycarbonate filters (Unipore; $0.4 \mu \mathrm{m}$ pore size). The filters were washed with $20 \mathrm{ml} 2 \mathrm{M}-\mathrm{NaCl}$, dried at $60^{\circ} \mathrm{C}$ for $25 \mathrm{~min}$, and counted in a 2,5-diphenyloxazole/1,4-di-2-(5-phenyloxazolyl)benzene/toluene scintillation mixture, utilizing a full tritium channel.

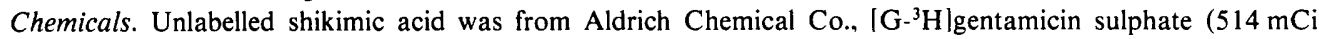

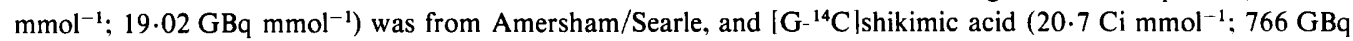
$\mathrm{mmol}^{-1}$ ) was from New England Nuclear. Unlabelled gentamicin and kanamycin sulphates were from Sigma.

Incorporation of $\left[{ }^{14} \mathrm{C} \mid\right.$ shikimic acid into menaquinone. The procedures were those described previously (Taber et al., 1978).

\section{RESULTS}

\section{Effect of kanamycin on menaquinone biosynthesis}

Since many of our experiments required that menaquinone continue to be synthesized from shikimic acid in the presence of aminoglycosides, it was necessary to establish that the antibiotics were not inhibiting the uptake of shikimic acid or its conversion to menaquinone. Accordingly, rates of menaquinone synthesis from $\left[{ }^{14} \mathrm{C}\right]$ shikimic acid (Taber et al., 1978) 


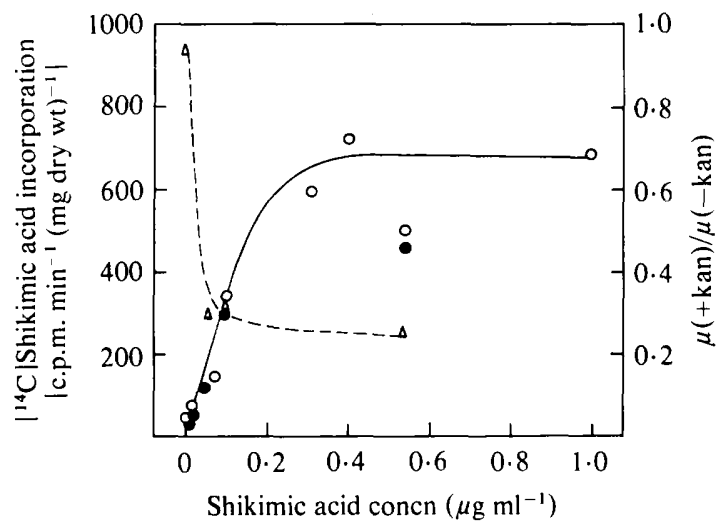

Fig. 1

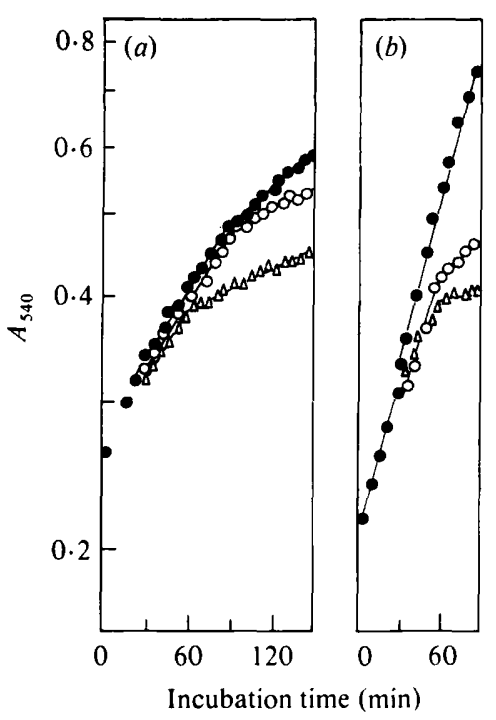

Fig. 2

Fig. 1. Effect of kanamycin on growth inhibition and on the synthesis of menaquinone. Strain RB 163(men) was grown overnight in TG medium $+0.01 \mu \mathrm{g}$ shikimic acid ml-1; two $20 \mathrm{ml}$ volumes of the same medium were inoculated to give an $A_{540}$ of 0.07 to 0.08 and shaken at $37^{\circ} \mathrm{C}$ until $A_{540}$ reached $0 \cdot 15$. Kanamycin $\left(1.5 \mu \mathrm{g} \mathrm{ml}^{-1}\right)$ was then added to one of the two flasks, and growth was continued until $A_{540}$ was 0.3 to 0.4 (at these low concentrations of kanamycin and shikimic acid. growth inhibition was not significant). $\left[{ }^{14} \mathrm{C} /\right.$ Shikimic acid $\left(0.024 \mu \mathrm{Ci} ; 20.7 \mathrm{Ci} \mathrm{mmol}^{-1}\right)$ was then added together with sufficient unlabelled shikimic acid to give the appropriate final concentrations. Growth measurements were continued, and $1.0 \mathrm{ml}$ samples were analysed for conversion of $\left[{ }^{14} \mathrm{C}\right]$ shikimic acid to $\left[{ }^{14} \mathrm{C} /\right.$ menaquinone as described previously (Taber et al., 1978). Rates of incorporation of $\left[{ }^{14} \mathrm{C}\right.$ /shikimic acid into TCA-precipitable fractions in the absence (O) and presence (O) of $1.5 \mu \mathrm{g}$ kanamycin $\mathrm{ml}^{-1}$ were calculated over the initial $20 \mathrm{~min}$ of exposure to $\left[{ }^{14} \mathrm{C}\right.$ lshikimic acid. The ratio $(\Delta)$ of specific growth rates $[\mu(+k a n) / \mu(-k a n)]$ was calculated for the period 20 to $50 \mathrm{~min}$ after addition of shikimic acid, utilizing the equivalence $\mu=0.693 /$ mass doubling time.

Fig. 2. Effect of menaquinone concentration on the sensitivity of strain RB163(men) to growth inhibition by gentamicin. Cultures were grown overnight in SMG $+0.01 \mu \mathrm{g}$ shikimic acid $\mathrm{ml}^{-1}$, then inoculated into SMG containing (a) 0.01 or $(b) 0.1 \mu \mathrm{g}$ shikimic acid ml-1. After growth to an $A_{540}$ of about $0 \cdot 3$, the cultures were divided into three portions. Two received gentamicin $\left(2 \cdot 0 \mu \mathrm{g} \mathrm{ml}^{-1}, \mathrm{O}\right.$; $20 \mu \mathrm{g} \mathrm{ml}^{-1}, \Delta$ ), and the third received no addition (O); growth was measured at $5 \mathrm{~min}$ intervals thereafter.

were measured for cultures of strain RB163(men) growing with various shikimic acid concentrations in the presence and absence of either kanamycin or gentamicin. The results for kanamycin are shown in Fig. 1. At very low shikimic acid concentrations $\left(0.01 \mu \mathrm{g} \mathrm{m}^{-1}\right)$, there was little inhibition of growth by the aminoglycoside, and rates of $\left[{ }^{14} \mathrm{C}\right.$ lshikimic acid incorporation into menaquinone were very low. As the concentration of shikimic acid was increased, growth inhibition by kanamycin became significant, but initial rates of menaquinone synthesis were unaffected. Incorporation of $\left[{ }^{14} \mathrm{C}\right]$ shikimic acid continued as a linear function of shikimic acid concentration up to 0.2 to $0.3 \mu \mathrm{g} \mathrm{ml}^{-1}$, after which shikimic acid uptake or the menaquinone synthesis system became saturated. Although the initial rates ( 0 to $20 \mathrm{~min}$ ) of menaquinone synthesis are shown in Fig. 1, it was clear from the incorporation plots (from which Fig. 1 was derived) that the $\left[{ }^{14} \mathrm{C}\right]$ shikimic acid incorporation rates between 20 and 50 min were also relatively unaffected by kanamycin. Similar results (not shown) were obtained with gentamicin. It would appear that menaquinone synthesis continues essentially unabated in the presence of growth-inhibitory concentrations of aminoglycosides. 
Table 1. Effect of menaquinone concentration on the sensitivity of strain RB163(men) to growth inhibition by gentamicin

\begin{tabular}{|c|c|c|c|c|}
\hline \multirow{3}{*}{$\begin{array}{c}\text { Shikimic acid } \\
\text { concentration } \\
\left(\mu \mathrm{g} \mathrm{ml}^{-1}\right)\end{array}$} & \multicolumn{4}{|c|}{ Ratio of specific growth rates $\mid \mu(+$ gen $) /\left.\mu(-$ gen $)\right|^{*}$} \\
\hline & \multicolumn{2}{|c|}{$2.0 \mu \mathrm{g}$ gentamicin $\mathrm{ml}^{-1}$} & \multicolumn{2}{|c|}{$20 \mu \mathrm{g}$ gentamicin $\mathrm{ml}^{-1}$} \\
\hline & $0-25 \mathrm{~min}$ & $25-50 \mathrm{~min}$ & $0-25 \mathrm{~min}$ & $25-50 \mathrm{~min}$ \\
\hline 0.01 & $1 \cdot 0$ & 0.98 & 0.98 & 0.28 \\
\hline 0.05 & $1 \cdot 0$ & 0.80 & 0.61 & $0 \cdot 14$ \\
\hline $0 \cdot 10$ & $1 \cdot 0$ & 0.20 & 0.55 & 0.09 \\
\hline 1.0 & 1.0 & 0.44 & 0.46 & 0.11 \\
\hline
\end{tabular}

* Derived from experiments of the type shown in Fig. 2 . The ratio $\mu(+\mathrm{gen}) / \mu(-\mathrm{gen})$ was calculated by measuring mass doubling times over the periods 0 to $25 \mathrm{~min}$ and 25 to 50 min following the addition of 2.0 or $20 \mu \mathrm{g}$ gentamicin $\mathrm{ml}^{-1}$.

\section{Growth inhibition by gentamicin as a function of menaquinone concentration}

Because our studies on aminoglycoside transport required the use of radioactively labelled antibiotic, we studied the growth-inhibitory effects of gentamicin, since this compound was readily available in tritiated form from commercial sources and is closely related in structure to several other aminoglycosides. These growth-inhibitory effects were measured as a function of the menaquinone content of the cells, at low and at high gentamicin concentrations $(2.0$ and $20 \mu \mathrm{g} \mathrm{m}^{-1}$ ). Two such experiments are illustrated in Fig. 2, and the growth inhibition effects are summarized in Table 1.

At the lower gentamicin concentration $\left(2.0 \mu \mathrm{g} \mathrm{ml}^{-1}\right)$, and at all menaquinone concentrations tested, a monophasic growth inhibition response occurred in the presence of the antibiotic. Following an initial uninhibited period of approximately $25 \mathrm{~min}$, a second, inhibited phase was seen (Fig. 2), during which the culture followed a lower rate of exponential growth. The severity of inhibition was related to the menaquinone content of the cells (Table 1), with maximal inhibition occurring at 5 to $10 \%$ or higher of the normal menaquinone content $(0.05$ to $0 \cdot 10 \mu \mathrm{g}$ shikimic acid $\mathrm{ml}^{-1}$ ).

The higher gentamicin concentration $\left(20 \mu \mathrm{g} \mathrm{ml}^{-1}\right)$ elicited a biphasic growth inhibition response at all but the lowest menaquinone concentration tested. As illustrated in Fig. $2(b)$, a moderate inhibition of growth over the initial $25 \mathrm{~min}$ was followed abruptly by a severe growth inhibition. Over both periods, maximal inhibition required that only 5 to $10 \%$ of the normal menaquinone content be present (Table 1).

\section{Menaquinone requirement for aminoglycoside accumulation}

Strain RB163(men) was shown previously to have a very low rate of kanamycin accumulation when grown in limiting shikimic acid to induce menaquinone deficiency (Taber \& Halfenger, 1976). However, the conditions of uptake were not optimal, and the unavailability of radioactively labelled aminoglycosides other than streptomycin made extensive investigation of the uptake characteristics impractical. More recently, the commercial availability of $\left[{ }^{3} \mathrm{H}\right.$ |gentamicin has improved the prospects for study of aminoglycoside accumulation.

Since growth inhibition of strain RB163(men) by gentamicin showed a striking dependence on menaquinone (Table 1), we measured the uptake of $\left[{ }^{3} \mathrm{H} \mid\right.$ gentamicin as a function of the menaquinone content of the cells. With an external gentamicin concentration of $23 \mu \mathrm{g} \mathrm{ml}^{-1}$, there was no accumulation at all if menaquinone was completely lacking (Fig. 3). When the cells had a very low content of menaquinone ( 1 to $5 \%$ of normal), there was a significant rate of accumulation of gentamicin: maximal rates were achieved with cells having 5 to $10 \%$ of the normal menaquinone content, and no further increase in rate was seen even when the cells had $100 \%$ of the normal menaquinone content. There was a strong correlation between the rates 


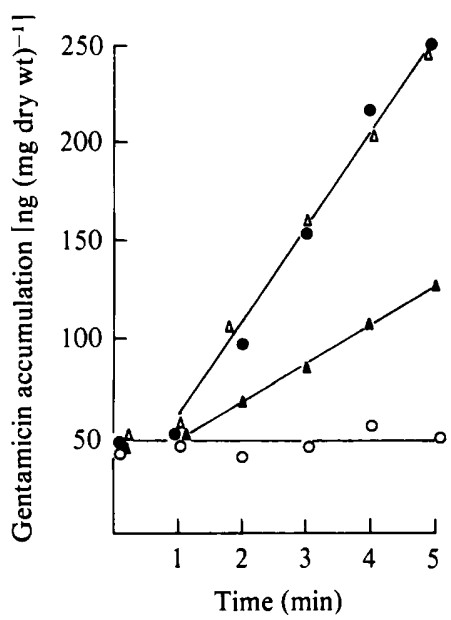

Fig. 3

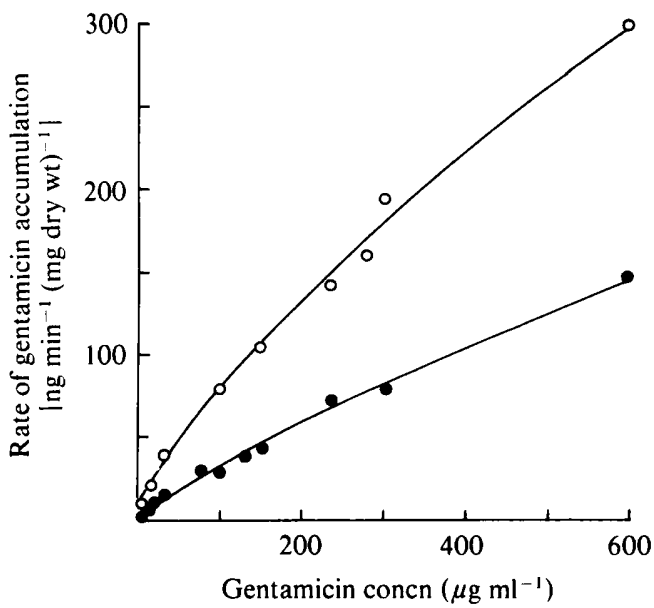

Fig. 4

Fig. 3. Menaquinone requirement for gentamicin uptake. Strain RB163(men) was grown overnight in SMG $+0.01 \mu \mathrm{g}$ shikimic acid $\mathrm{ml}^{-1}$, then diluted $1: 20$ into SMG containing different concentrations of shikimic acid. $\left[{ }^{3} \mathrm{H} \mid\right.$ Gentamicin uptake was measured as described in Methods, after growth of the cultures to early-exponential phase $\left(A_{540}=0.3\right)$ in medium with no shikimic acid (O), or $0.05(\Delta), 0.1$ $(\triangle)$ or $1.0(O) \mu \mathrm{g}$ shikimic acid $\mathrm{ml}^{-1}$. The external gentamicin concentration was $23 \mu \mathrm{g} \mathrm{ml}^{-1}$.

Fig. 4. Gentamicin accumulation by strain RB163(men) as a function of gentamicin concentration. Accumulation of $\left[{ }^{3} \mathrm{H}\right.$ |gentamicin was measured as in Fig. 3, after growth to an $A_{540}$ of about 0.3 in medium containing $0.05(O)$ or $5(\mathrm{O}) \mu \mathrm{g}$ shikimic acid $\mathrm{ml}^{-1}$.

of accumulation (Fig. 3) and the extent of growth inhibition (Table 1) at given menaquinone concentrations, suggesting a causal relationship between uptake rate and growth inhibition by gentamicin.

\section{Saturation of the gentamicin accumulation system}

If, as suggested by Bryan \& Van den Elzen (1977), the respiratory quinones are directly or indirectly involved in establishment of aminoglycoside receptor sites, then a decrease in the menaquinone concentration of $B$. subtilis RB163(men) should reduce the number of these sites. This would have the effect of decreasing the maximal velocity of gentamicin uptake observed at high gentamicin concentrations. The result of this approach is shown in Fig. 4, where the rates of uptake are plotted as a function of extracellular gentamicin concentration. When the cellular menaquinone concentration was $100 \%$ of normal, the system for gentamicin uptake was non-saturable up to $600 \mu \mathrm{g}$ gentamicin $\mathrm{ml}^{-1}$. Similar concentration dependence curves were obtained for menaquinone concentrations down to about $10 \%$ of normal (results not shown). When the cellular concentration of menaquinone was further decreased (to about $5 \%$ of normal: Fig. 4), substantially lower rates of accumulation were observed. Measurements at very low menaquinone concentrations (e.g. $<1 \%$ of normal) were not made systematically, because of difficulties in establishing the uptake rates at low gentamicin concentrations under these conditions. However, it seems clear that the maximum rate of uptake can be substantially lowered by menaquinone limitation, and this can be interpreted as limitation in the number of uptake sites.

\section{DISCUSSION}

We must conclude from the present study and from previous work that the presence of lipophilic quinones in bacterial membranes is crucial to the uptake process for amino- 
glycosides in amounts necessary to inhibit growth. The ubiquinone-deficient Escherichia coli strain AN66 (Newton et al., 1972) has been studied by Bryan \& Van den Elzen (1977) and found to show a pronounced lowering in the maximal rate of accumulation (EDP-II) of gentamicin and streptomycin, and a greatly extended initial uptake phase (EDP-I). Similarly, in strictly anaerobic bacteria having natural resistance to aminoglycosides, a strong correlation exists between lack of occurrence of lipophilic quinones and inability to accumulate gentamicin or dihydrostreptomycin (Bryan et al., 1979).

The mechanisms through which quinone deficiency exerts its effects on aminoglycoside uptake may, however, be complex. Previous work in our laboratory on the physiological effects of menaquinone deficiency in B. subtilis (Farrand \& Taber, $1973 \mathrm{a}$, b; Taber et al., 1972) suggests that at least $90 \%$ of menaquinone in $B$. subtilis can be deleted metabolically without a decline in the rates of electron transport, oxygen utilization, or growth. The present findings emphasize the importance of the residual $10 \%$ menaquinone for growth inhibition by aminoglycosides. Indeed, when the menaquinone concentration is less than $1 \%$ of normal, no growth inhibition by low gentamicin concentrations is seen. Since growth inhibition and gentamicin accumulation are maximal at 5 to $10 \%$ menaquinone, it would seem that the bulk of the menaquinone present in the $B$. subtilis membrane does not participate in aminoglycoside uptake. This conclusion is supported by our recent finding that the sensitivity of gentamicin uptake to inhibition by divalent ions does not change as the menaquinone content is decreased from 100 to $10 \%$ of normal $(\mathrm{H}$. W. Taber \& B. J. Sugarman, unpublished results). Also, our results show that the uptake system gives no evidence of saturation unless the cellular menaquinone content is decreased to below $10 \%$. Unpublished results of M. Muir (cited in Muir \& Wallace, 1979) suggest that quinone concentrations rather than rates of electron transport determine the rate of streptomycin accumulation by $E$. coli. One interpretation of these observations is to suppose that the quinone is a binding site or even forms part of a transport complex. This concept has been advanced by Bryan and his colleagues (Bryan \& Van den Elzen, 1977; Bryan et al., 1980) and has much to recommend it. Lipophilic quinones are undoubtedly mobile in the membrane and may serve as proton porters as well. Menaquinone (in $B$. subtilis) could function both to aid in maintaining the proton motive force, and, as the deprotonated quinol form, to serve as an anionic membrane binding site for aminoglycosides.

This work was supported in part by Research Career Development Award 5-KO4-AI-70655 from the National Institute of Allergy and Infectious Diseases to H. W. Taber, and by Research Grant PCM-7924188 from the National Science Foundation.

\section{REFERENCES}

AnAgnostopoulos, C. \& Spizizen, J. (1961). Requirements for transformation in Bacillus subtilis. Journal of Bacteriology 81, 741-746.

Bisschop, A., DEJong, L., Lima Costa, M. E. \& Konings, W. N. (1975). Relation between reduced nicotinamide adenine dinucleotide oxidation and amino acid transport in membrane vesicles from Bacillus subtilis. Journal of Bacteriology 121, 807-813.

Bryan, L. E. \& VAN den Elzen, H. M. (1976). Streptomycin accumulation in susceptible and resistant strains of Escherichia coli and Pseudomonas aeruginosa. Antimicrobial Agents and Chemotherapy 9.928-938.

Bryan, L. E. \& VAN DEN Elzen, H. M. (1977). Effects of membrane-energy mutations and cations on streptomycin and gentamicin accumulation by bacteria: a model for entry of streptomycin and gentamicin in susceptible and resistant bacteria.
Antimicrobial Agents and Chemotherapy 12, 163177.

Bryan, L. E., Haraphongse, R. \& Van den Elzen, H. M. (1976). Gentamicin resistance in clinical isolates of Pseudomonas aeruginosa associated with diminished gentamicin accumulation and no detect able enzyme modification. Journal of Antibiotics 29. 743-753.

Bryan, L. E., Kowànd, S. K. \& Van den Elzen, H. M. (1979). Mechanism of aminoglycoside resistance in anaerobic bacteria: Clostridium perfringens and Bacteroides fragilis. Antimicrobial Agents and Chemotherapy 15, 7-13.

Bryan, L. E., Nicas, T., Holloway, B. W. \& Crowther, C. (1980). Aminoglycoside-resistant mutation of Pseudomonas aeruginosa defective in cytochrome $c_{552}$ and nitrate reductase. Antimicrobial Agents and Chemotherapy 17. 7179. 
FARrAND, S. K. \& TABER, H. W. (1973 a). Pleiotropic menaquinone-deficient mutant of Bacillus subtilis. Journal of Bacteriologv 115, 1021-1034.

FARrand, S. K. \& TABer, H. W. (1973b). Physiological effects of menaquinone deficiency in Bacillus subtilis. Journal of Bacteriology 115, 1035-1044.

HöltJE, J.-V. (1978). Streptomycin uptake via an inducible polyamine transport system in Escherichia coli. European Journal of Biochemistry 86, 345351 .

HÖLTJE, J.-V. (1979a). Induction of streptomycin uptake in resistant strains of Escherichia coli. Antimicrobial Agents and Chemotherapy 15, 177181.

HöltJE, J.-V. (1979b). Regulation of polyamine and streptomycin transport during stringent and relaxed control in Escherichia coli. Journal of Bacteriology 137, 661-663.

Muir, M. E. \& Wallace, B. J. (1979). Isolation of mutants of Escherichia coli uncoupled in oxidative phosphorylation using hypersensitivity to streptomycin. Biochimica et biophysica acta 547, 218-229.

Newton, N. A., Cox, G. B. \& Gibson, F. (1972). Function of ubiquinone in Escherichia coli: a mutant strain forming a low level of ubiquinone. Journal of Bacteriology 109, 69-73.

Plate, C. (1976). Mutant of Escherichia coli defective in response to colicin $\mathrm{K}$ and in active transport. Journal of Bacteriology 125, 467-474.

TABER, H. \& Halfenger, G. M. (1976). Multipleaminoglycoside-resistant mutants of Bacillus subtilis deficient in accumulation of kanamycin. Antimicrobial Agents and Chemotherapy 9, 251-259.

TABer, H. W., Farrand, S. K. \& Halfenger, G. M. (1972). Genetic regulation of membrane components in Bacillus subtilis. In Spores $V$, pp. 140-147. Edited by H. O. Halvorson, R. S. Hanson \& L. L. Campbell. Washington, D.C.: American Society for Microbiology.

Taber, H., Pomerantz, B. J. \& Halfenger, G. M. (1978). Near UV-induced growth delay studied in a menaquinone-deficient mutant of Bacillus subtilis. Photochemistry and Photobiology 28, 191-196.

ThorbJarnardóttir, S. H., Magnúsdóttir, R. A., Eggertsson, G., Kagan, S. A. \& Andrésson, O. S. (1978). Mutations determining generalized resistance to aminoglycoside antibiotics in Escherichia coli. Molecular and General Genetics 161, 89-98. 